\title{
“Terra à Vista!": Explorando Outras Possibilidades em Análise do Discurso em Estudos Organizacionais
}

\author{
"Land Ahoy!": Exploring Other Possibilities in Organizational Studies Discourse \\ Analysis
}

\author{
Lilian Alfaia Monteiro \\ Doutora em Administração \\ Professora da Universidade Federal de Juiz de Fora \\ Rua José Lourenço Kelmer, s/n - Campus Universitário - Bairro São Pedro \\ CEP: 36036-900 - Juiz de Fora - MG \\ Telefone: (32) 2102-3533 - Ramal 202 \\ E-mail: lilian.alfaia@ufjf.edu.br \\ Ana Christina Celano Teixeira \\ Doutora em Administração \\ Professora do Ibmec/RJ no curso de mestrado profissional em Administração \\ Av. Presidente Wilson, 118 - Centro \\ 20030-020 - Rio de Janeiro, RJ - Brasil \\ Telefone: (21) (21) 3284-4000 - Ramal 4303 \\ e-mail: ana.teixeira@ibmec.edu.br
}

\begin{abstract}
Resumo
A partir do pressuposto de que o discurso constituiu e/ou constrói qualquer fenômeno sob interesse de pesquisa (organizações, indivíduos, realidade), buscamos neste ensaio trazer para o debate outras possibilidades de Análise de Discurso (AD) ainda pouco exploradas na academia brasileira em Estudos Organizacionais, de modo a enriquecer o campo metodologicamente. Para tanto, trazemos para além da Análise Crítica do Discurso, perspectiva predominante em Análise do Discurso, alternativas como a Arqueologia do Discurso e a Análise Conversacional. Por fim, efetuamos nossas considerações finais, a partir dos principais resultados alcançados pelo ensaio, destacando as novas possibilidades em AD, suas principais vantagens e diferenças essenciais.
\end{abstract}

Palavras-chave: Análise do Discurso; Análise Crítica do Discurso; Estudos Organizacionais; Arqueologia do Discurso; Análise Conversacional.

\begin{abstract}
From the assumption that the discouse constituted and/or build any phenomenon under academic research interest (organizations, individuals, reality), we seek in this essay bring to the debate other Discourse Analysis possibilities (AD) still little explored in Brazilian academy in Organizational Studies so as to enrich the methodologically field. Therefore, we bring in addition to Critical Discourse Analysis, as the dominant perspective in discourse analysis area, alternatives such as Archaeology Discourse and Conversation Analysis. Finally, we have made our final thoughts from the main results achieved by discussion, highlighting the new possibilities in $\mathrm{AD}$, its main advantages and essential differences.
\end{abstract}

Keywords: Discourse Analysis; Critical Discourse Analysis; Organizational Studies; Archaeology Discourse; Conversational Analysis. 


\section{Introdução}

Alvesson e Kärreman (2000a; 2000b; 2011) retomam o debate em torno da Análise do Discurso (AD), suas principais formas de utilização em Estudos Organizacionais, sua relação com o "linguistic turn" em ciências sociais, bem como, as possíveis consequências positivas e negativas desta crescente tendência no campo organizacional. A principal premissa desta retomada linguística é que o discurso constituiu e/ou constrói qualquer fenômeno sob interesse de pesquisa (organizações, indivíduos, realidade), ou seja, que a linguagem constrói a realidade organizacional, ao invés de apenas refleti-la (ALVESSON; KÄRREMAN, 2000a; 2000b; 2011; HARDY; LAWRENCE; GRANT, 2005).

Para Alvesson e Kärreman (2011), existem duas principais formas de Análise do Discurso: uma com "d" minúsculo e outra com " $\mathrm{D}$ " maiúsculo. A primeira tem foco no "micro-discurso" no qual o mundo social é construído de baixo para cima e a segunda tem foco nos "mega-discursos", voltados principalmente para sistemas de ideias desenvolvidos historicamente e que institucionalizam os chamados "regimes de verdade". Dada a complexidade e a ruptura com os demais tipos de AD (Análise Psicológica do Discurso, Análise Conversacional, Análise Crítica do Discurso, por exemplo), este último tipo de análise do discurso foi denominado por estes autores como "Estudos de Discursos do tipo Paradigmático" (PDS - Paradigm-type Discourse Studies), ganhando uma nova denominação específica para se diferenciar das demais, uma vez que este se refere ao estudo do surgimento de "metanarrativas".

Dado o crescente número de pesquisas envolvendo o método de $\mathrm{AD}$ em Estudos Organizacionais (ALVESSON; KÄRREMAN, 2011), buscamos neste ensaio trazer para o debate possibilidades pouco exploradas na academia brasileira para analisar o discurso nas pesquisas em organizações, de modo a enriquecer o campo metodologicamente. Visto que há um predomínio de um método de $\mathrm{AD}$ sobre os demais - Análise Crítica do Discurso (ALVESSON; KÄRREMAN, 2011), optamos por ampliar este debate a partir da análise de possibilidades como a Arqueologia do Discurso (FOUCAULT, 1972; 1998), bem como a Análise Conversacional (HERITAGE, 2004; 2011).

A escolha por estas duas abordagens de AD se deve pelas possibilidades de pesquisa que podem ser realizadas em Estudos Organizacionais, ampliando ainda mais o campo. A Arqueologia foucaultiana possui o pressuposto de que o discurso é estabelecido não na língua e nas circunstâncias que utiliza o discurso, mas sim no próprio discurso enquanto prática. Neste caso, o discurso é definido pelas relações que proporcionam a formação dos processos (econômicos e sociais, instituições, diferentes formas de comportamento, normas, técnicas, classificações e distintos modos de caracterização) de formação discursiva (FOUCAULT, 1972, p. 61).

Já a Análise Conversacional toma como premissa que a conversação é o local primordial da sociabilidade humana e que a interação social incorpora uma ordem institucional e moral, relacionando-se tanto à identidade pessoal quanto às instituições sociais (HERITAGE, 2004). Seu foco de análise são as falas ou diálogos, que ocorrem na prática cotidiana e em um contexto institucional, analisando dentro desta conjuntura a ação e a intersubjetividade.

O ensaio está dividido em quatro tópicos principais. Primeiramente, retomamos a contribuição da Análise Crítica do Discurso, perspectiva predominante em AD. Em seguida, nos aprofundamos na Arqueologia do Discurso, a partir de análise teórica e demonstração de estudos empíricos. Após esta etapa, efetuamos os mesmos procedimentos anteriores em relação à Análise Conversacional. Por fim, efetuamos nossas considerações finais, a partir dos principais resultados alcançados pelo ensaio, das possibilidades de adoção de novos métodos de $\mathrm{AD}$ e de suas principais vantagens e diferenças essenciais. 


\section{Contribuição da Análise Crítica do Discurso}

A Análise Crítica do Discurso (ACD), no amplo conjunto das várias vertentes da análise de discurso, trata sobre a conexão entre o poder e o significado explorando como este(s) processo(s) de construção social leva e mantém a uma determinada realidade que não é questionada. Esta realidade inquestionável, 'natural' é caracterizada em geral por relações desiguais de poder e pela posição hegemônica - e, portanto, vantajosa - de alguns atores à custa de outros (PHILLIPS; HARDY, 2002).

A ACD procura compreender quais estruturas, estratégias e outras propriedades de textos, falas, interações verbais ou eventos comunicativos são exercidos nos modos de produção e reprodução da estrutura de dominação (VAN DIJK, 1993). Para a obtenção deste objetivo, a ACD traz uma grande variedade de abordagens de análises sociais de discurso (FAIRCLOUGH; WODAK, 1997; PÊCHEUX, 1982; WODAK; MEYER, 2001) que podem apresentar grande diversidade em termos de teoria, metodologia e tipo de pesquisa (ALVESSON; KÄRREMAN, 2000a; FAIRCLOUGH, 1995; 2001; 2003; MUMBY, 2004; PHILLIPS; HARDY, 2002; VAN DIJK, 1993; 2006). Aquele que é considerado o maior expoente desta grande matriz, Norman Fairclough, está preocupado com processos de mudança social em termos do seu aspecto discursivo (FAIRCLOUGH, 2001; 2005a; 2005b).

Caracterizada por uma ontologia realista social, essa abordagem considera: a) a realidade social como uma dinâmica formada tanto pelas estruturas sociais abstratas, quanto pelos eventos sociais concretos; b) uma visão dialética da relação entre estrutura e agência, bem como das relações entre o discurso e outros elementos ou "momentos" de práticas sociais e eventos sociais (FAIRCLOUGH, 2005a). Tal dinâmica pressupõe que o discurso "internaliza" elementos sociais e é por estes "internalizado" (HARVEY; REED, 1996).

Por ter foco na dinâmica de poder, conhecimento e ideologia presente nos processos discursivos, a ambição da ACD não é tão somente analisar a linguagem como forma de identificação de significados sociais, mas desvelar o controle, a dominação, a discriminação, o poder de grupos expressos na linguagem (FAIRCLOUGH; WODAK, 1997). Se as relações de poder são legitimadas por meio da linguagem, ela é também uma prática social.

Segundo Titscher e Jenner (2000), um dos pressupostos básicos é a ideia de que a linguagem repete, e portanto reforça, injustiças, assimetrias e diferenças, legitimando-as. Não à toa, já foram objetos de pesquisa sob a perspectiva da $\mathrm{ACD}$, o discurso de partidos políticos ou governos (WODAK, 1989; FAIRCLOUGH, 1989; 2000), racismo (VAN DIJK, 1993), economia (FAIRCLOUGH, 1995; CHOULIARAKI; FAIRCLOUGH, 1999), questões de gênero (WALSH, 1998), discursos gerenciais (FAIRCLOUGH, 2010. No Brasil, a ACD é pouco usada, mas dentro da Administração, a área de estudos organizacionais e críticos apresenta alguns exemplos (BARROS et al, 2009; ROSA FILHO, 2010).

Para Fairclough (1989), o termo 'discurso' refere-se ao processo de interação social, possuindo, portanto, uma dimensão histórica e contextual. A análise dos discursos permite explorar as relações entre texto e contexto (PHILLIPS; HARDY, 2002; FAIRCLOUGH, 2003) desvelando como os significados são atribuídos e como a realidade social é construída, mantida, modificada e experimentada pelos indivíduos (PHILLIPS; HARDY, 2002). A ACD preocupa-se com dois aspectos constitutivos dos discursos: o fato de serem instrumentos de poder e controle e sua capacidade de construção social da realidade.

Segundo Pedrosa (2010), Fairclough (2003) localiza a ACD teoricamente em uma abordagem que vê o discurso como um dos diversos momentos de prática social, tendo em vista que todas as práticas incluem os seguintes elementos: atividade produtiva, meios de produção, relações sociais, identidades sociais, valores culturais, consciências e semioses. 
Esses elementos se acham relacionados dialeticamente como construtores e construídos e, embora diferentes, não se apresentam de forma discreta.

As semioses, especificamente, figuram três maneiras nas práticas sociais (que constituem campos sociais, instituições e organizações). Primeiramente, como parte da atividade social, parte da ação e da interação. Em segundo lugar, como parte das representações. Por fim, como maneiras de ser, na constituição das identidades (FAIRCLOUGH, 2003). Como parte da atividade social, a semiose constitui "gêneros", ou seja, maneiras diversas de (inter)agir em seu específico aspecto semiótico (por exemplo reuniões em vários tipos de organizações, entrevistas políticas, artigos de notícias na imprensa e revisões de livros). Assim, na representação e auto-representação das práticas sociais, a semiose constitui o próprio discurso (FAIRCLOUGH; WODAK, 1997).

Análises de textos incluem análise 'interdiscursiva' de como gêneros, discursos e estilos se articulam conjuntamente. Estas são categorias que são distintas e relacionadas no nível das práticas sociais (como elementos das ordens de discurso). No nível dos eventos sociais - textos - eles são desenhados de maneira que dão origem a hibridez ou "mistura" das categorias, ou seja, um texto pode ser híbrido com relação aos gêneros, discursos e/ou estilos (por exemplo, a "mercantilização" do ensino superior é em parte uma questão de textos que 'misturam' gêneros e estilos, assim como mais evidentemente os discursos da educação e do mercado (FAIRCLOUGH, 1993).

A análise interdiscursiva é importante característica que distingue esta versão da ACD. Ela permite que a incorporação de elementos do "contexto" na análise dos textos demonstre a relação entre eventos ocasionais concretos e práticas sociais mais duráveis, além de identificar a inovação e mudança nos textos. Desta forma ela tem um papel de mediação ao permitir a conexão de características lingüísticas e semióticas detalhadas dos textos com os processos de mudança social em larga escala (FAIRCLOUGH, 1993).

Para o autor, mudança social inclui mudança nas práticas sociais e na rede de práticas sociais. Ou seja, como as práticas sociais estão articuladas na constituição de campos sociais, instituições e organizações, e nas relações entre ordens de discurso (e, portanto, em mudanças em gêneros, discursos e estilos e relações entre gêneros, discursos e estilos). Acima de tudo, mudanças na semiose (ordens de discurso) são uma precondição para processos mais amplos de mudança social - por exemplo, uma rede elaborada de gêneros é uma pré-condição para 'globalização' se entendermos a última como um aumento de possibilidades para 'ação à distância', e o 'estiramento' de relações de poder (GIDDENS, 1990). Segundo Fairclough (2003), frequentemente os processos de mudança mais amplos podem ser vistos iniciando em uma mudança no discurso. Se pensarmos na dialética do discurso em termos históricos, em termos de processos de mudança social, a questão que emerge é: sob quais maneiras e quais condições os processos de internalização acontecem?

Apesar dos benefícios quanto à utilização da ACD para se analisar discurso organizacional, buscamos neste ensaio evidenciar outras perspectivas ainda pouco exploradas. Na seção seguinte apresentaremos como a Arqueologia do Discurso pode ser empregada nos Estudos Organizacionais e como seu uso pode ampliar ainda mais campo com pesquisas que tratam do discurso a partir de uma perspectiva diferenciada. Desta forma, a partir deste ponto começamos a vislumbrar "novas terras" no horizonte, novas possibilidades de AD.

\section{Arqueologia do Discurso}

Apesar de não ser amplamente difundida na academia brasileira de Administração, a Arqueologia inspirada na AD de Michel Foucault (filósofo e historiador), é definida por 
Alvesson e Kärreman (2011) como a AD com "D" maiúsculo, na qual os discursos representam os corpos de conhecimento e, por isso, são expressões das relações de poder e saber que formam sistematicamente o objeto do qual falam. Para o autor, o discurso é mais do que uma interação linguística do cotidiano, ele é voltado para a formação de "regimes de verdade" a partir de uma relação de sistemas de ideias (ALVESSON; KÄRREMAN, 2000a; 2000b; 2011). Fairhurst (2007) ressalta que, para Foucault, a relação "poder/saber" é estabelecida por meio de diferentes recursos discursivos como padrões de fala, ideias, lógicas e premissas, que constituem os sujeitos e objetos.

Para Foucault os pensamentos são estruturados para dar uma solução e, no mundo humano, isso está sempre sujeito ao trabalho do poder, uma vez que o poder, mais que um 'antagonismo' essencial, é intrínseco à lógica agonística da disparidade. Neste sentido, o discurso é a expressão do poder no âmago dos problemas, pois precede a resposta por meio de sua prévia estruturação. Ou seja, o entendimento próprio de uma solução se dá pela forma como o problema foi, antes de tudo, estruturado. Desta forma, o discurso passa a não ser mais um meio neutro de comunicação sobre o mundo (COOPER; BURRELL, 2007).

$\mathrm{Na}$ sua analítica do poder, o filósofo descreve que as formas de racionalidade que atuam nos processos de dominação não são distintas a outras formas de poder colocadas em ação, como, por exemplo, o saber ou a técnica. Ao contrário, o que existe é uma troca, transmissões, transferências, interferências, que rejeitam qualquer conceito de isomorfismo racional e que atuam simultaneamente em uma interconexão fechada, mas ao mesmo tempo, múltipla. Desse modo, não há uma lei geral (FOUCAULT, 2000a).

Em sua obra, Foucault utiliza uma perspectiva histórica para ressaltar que as diferentes modalidades de poder são capazes de produzir uma organização de práticas e discursos que a sociedade legitima como "saber". Desta forma, o saber é produzido por práticas heterogêneas de poder, em oposição à visão amplamente aceita na ciência e na filosofia na qual o saber é produzido a partir da descoberta da verdade (CALÁS; SMIRCICH, 1991).

Foucault (2000a) defende ainda que, mais importante do que estudar a história das ideias em sua evolução é ver debaixo das ideias, como puderam surgir alguns objetos possíveis de saberes. Segundo o autor, o problema nunca deixou de ser a busca pela verdade, o dizer verdadeiro e a relação entre o dizer verdadeiro e as formas de reflexividade, ou seja, a reflexividade de si sobre si. Neste caso, o autor destaca que um dos hábitos mais nocivos do pensamento contemporâneo é analisar o momento presente como sendo precisamente aquele que rompe ou até mesmo que é o momento ápice, o tempo da realização ou o da aurora que retorna.

Para o autor, a história consiste em caracterizar o que somos, mas de acordo com as linhas da vulnerabilidade da atualidade, buscando também apreender por onde e como o que existe hoje poderia não ser mais como é. Logo, não cabe ao intelectual o papel de afirmar: já que isso existe, logo continuará existindo. Ao contrário, a história deve mostrar que o que é jamais foi, e que é "sempre na confluência dos encontros, dos acasos, no curso da história frágil, precária, que são formadas as coisas que nos dão a impressão de serem as mais evidentes" (FOUCAULT, 2000a, p. 325). Portanto, a partir do conhecimento de como as coisas foram feitas é possível que se saiba também como elas podem ser desfeitas.

Aproximando-se de uma abordagem pós-estruturalista, Foucault desenvolve sua Arqueologia como método para se executar a Análise do Discurso. Segundo Peci (2005), o autor se afasta de um posicionamento objetivista e/ou subjetivista do discurso ao denominar discurso as relações que possibilitam o processo de formação dos objetos, neste caso, o processo de formação discursiva. Tais relações são estabelecidas entre processos econômicos e sociais, instituições, diferentes formas de comportamento, normas, técnicas, classificações e distintos modos de caracterização, mas estas relações não estão presentes no objeto, mas sim no limite do discurso, caracterizando, deste modo, o discurso como prática. Para o autor 
"essas relações caracterizam não a língua que utiliza o discurso, não as circunstâncias em que ele se desenvolve, mas o próprio discurso enquanto prática." (FOUCAULT, 1972, p. 61).

Emerge daí o uso do conceito das "práticas discursivas" em estudos com esta perspectiva foucaultiana (PECI, 2005). Sendo assim, o método arqueológico não se prende ao julgamento do que é a verdade ou a falsidade nos enunciados propostos nos domínios sob análise. Neste caso, interessa pouco a Foucault esclarecer/discutir a veracidade ou a falsidade dos ensinamentos da medicina, da psiquiatria ou das ciências humanas, mas sim analisar o que foi dito por estas ciências, tendo seus discursos como objeto de estudo, a fim de esclarecer as regras que regulam os discursos científicos (RABINOW; DREYFUS, 1995; FONSECA, 2001; MOTTA; ALCADIPANI, 2004).

Assim sendo, o discurso para Foucault não é apenas um conjunto de signos e sim práticas que formam sistematicamente os objetos de que falam. A utilização destes signos vai além do que a simples designação de coisas. Cabe ao arqueólogo fazer com que este algo a mais apareça e seja descrito (FOUCAULT, 1972). Visto isto, o autor ressalta que, para a análise do discurso, é preciso efetuar a descrição do "arquivo" buscando encontrar as regras que governam sua auto-regulação (BURRELL, 1998).

No entanto, o autor não pretende encontrar as relações que seriam secretas, escondidas, mais silenciosas ou profundas do que a própria consciência dos homens. Em oposição, ele vai buscar definir as relações que estão na superfície dos discursos com o objetivo de tornar visível o que apenas é invisível por estar muito na superfície das coisas (FOUCAULT, 2000b).

Alvesson e Kärreman (2011) ressaltam que poucos trabalhos com este método são empíricos, em geral as pesquisas são efetuadas com base em análise textual. Entretanto, já observamos muitos estudos em teorias organizacionais que se valeram da AD com " $D$ " maiúsculo ou Arqueologia do Discurso Foucaultiana (KNIGHTS; MORGAN, 1991; TOWNLEY, 1993; CALÁS; SMIRCICH, 1991). Sendo assim, analisaremos aqui a pesquisas de Leclercq-Vandelannoitte (2011) "Organizations as Discursive Constructions: A Foucauldian Approach”.

Neste estudo Leclercq-Vandelannoitte (2011) problematiza o postulado de que a comunicação constitui as organizações (CCO - Communication Constitutes Organizations). Diferentes pesquisas buscaram esclarecer a ideia de que a comunicação é constitutiva da organização (SMITH, 1993; McPHEE; ZAUG, 2000; FAIRHURST; PUTNAM, 2004), baseadas na premissa de que a comunicação produz e não apenas expressa a realidade organizacional (ASHCRAFT; KUHN; COOREN, 2009, p. 2).

Entretanto, Leclercq-Vandelannoitte (2011) aponta para as ambigüidades, lacunas e desafios para a compreensão do argumento de CCO. Para o autor, as condições em que as organizações são criadas por meio da comunicação não são claras. Desta forma, LeclercqVandelannoitte (2011) utiliza a Análise de Discurso Foucaultiana para examinar os efeitos dos discursos dominantes para melhor entender as relações entre tecnologia de comunicação, discurso, poder, conhecimento, disciplina e demais assuntos, articulando processos políticos dinâmicos que combinam elementos simbólicos e materiais para constituição organizacional. A escolha pela análise das tecnologias de comunicação se deu pela crescente difusão e mobilidade do chamado e-management, tornando-se um assunto chave para os Estudos Organizacionais a análise de como o discurso da tecnologia móvel impacta as organizações e a gestão.

No que se refere à parte empírica da pesquisa de Leclercq-Vandelannoitte (2011), destacaremos aqui como se deu o processo de coleta e análise de dados para a utilização da $\mathrm{AD}$ foucaultiana. $\mathrm{O}$ estudo foi conduzido na organização ABConstruction, entre janeiro de 2006 e julho de 2007, localizada principalmente na França, durante a implantação de um 
projeto de tecnologia móvel chamado Sesame, que tinha por finalidade a melhoria da gestão de dados e otimização dos processos.

A coleta de dados foi feita em três etapas centrais: entrevistas semi-estruturadas com gerentes e gestores de topo; entrevistas semi-estruturadas com gerentes operacionais e de nível médio; e observações diretas de campo. Foram efetuadas 32 entrevistas no total. Todas elas ocorreram no local de trabalho e foram gravadas e transcritas na íntegra. A primeira rodada de entrevistas foi realizadas entre janeiro e setembro de 2006, antes da implementação do projeto Sesame. A segunda rodada de entrevistas foi realizada entre setembro de 2006 e julho de 2007, após os tablet PCs terem sido implantados e utilizados por vários meses. Por fim, foram realizadas entrevistas adicionais em dezembro de 2007 com o intuito de obter uma visão mais ampla da evolução das práticas discursivas e do impacto organizacional da implantação móvel de Tecnologia da Informação (TI) na organização. Quanto à observação, foram visitados locais de trabalho dos entrevistados por mais de 10 dias (acompanhamento de quatro equipes), observando o trabalho do dia-a-dia dessas pessoas (LECLERCQVANDELANNOITTE, 2011).

No que tange à análise dos dados, após as entrevistas, o autor buscou identificar forças subjacentes, aspectos, princípios e efeitos do discurso organizacional. Além disso, buscou entender como as condições econômicas, históricas, culturais e sociais influenciaram o surgimento de discursos sobre a implantação de TI móvel, e como esses discursos potencialmente afetaram estruturas da empresa, relações de autoridade e modos de governança (relações de poder, sistemas de controle e disciplina). Assim como as entrevistas, as notas de campo também foram submetidas à análise de conteúdo qualitativa através de um processo de codificação temática. A codificação seguiu as seguintes etapas (LECLERCQVANDELANNOITTE, 2011):

- $\quad$ Codificação descritiva, armazenamento de informação que descreve o caso, incluindo pessoas e grupos envolvidos em todos os eventos e incidentes, os papéis e as atividades que desempenham, elementos contextuais que os membros da organização acreditam que a mudança organizacional influencia, além das ideias e dos argumentos desenvolvidos por estes ao descreverem suas ações e práticas. $\mathrm{O}$ uso da linguagem, pronomes e o humor também foram codificados;

- Codificação de tópicos dos principais construtos relacionados aos discursos organizacionais, estruturas, sistemas de controle, práticas individuais e as reações (reação à mudança, aspectos de resistência, movimentos de apropriação).

- $\quad$ Codificação analítica para interpretação dos construtos em seu contexto. $\mathrm{O}$ autor buscou analisar como condições no nível micro e macro impactam as relações de poder-conhecimento. Ou seja, como os discursos, subjetividades e autoridades emergem, se modificam, interagem e coevoluem. Para isto, examinou os eventos ao longo do tempo, identificando os impactos de um incidente nas relações de grupo, relações formais e informais, jogos de poder e processos diferentes.

Segundo Leclercq-Vandelannoitte (2011), para melhor entender como organização e comunicação são interligadas nas relações de CCO é preciso ir além de teorizações simplórias de poder, mas ao invés disso, reconhecer o caráter relacional do poder e como ele é incorporado em práticas discursivas, além de reconhecer o dualismo entre agência-estrutura em CCO. Neste caso, a abordagem foucaultina de discurso fornece uma concepção dialógica, relacional e contextualizada da realidade social, bem como o dualismo simbólico-material que define $\mathrm{CCO}$ como um conjunto de processos organizacionais que proporcionam relações dinâmicas na interseção de mundos simbólicos e materiais.

Os resultados da pesquisa empírica sugerem que a organização não é simplesmente comunicação ou discurso, mas sim relações entre tipos de processos distintos (McPHEE; 
ZAUG, 2000). A constituição de uma organização se dá no contexto das condições dinamicamente possíveis e restritas, sendo constituída em práticas discursivas e incorporada em recursos materiais. Tais condições de novas possibilidades são representadas em construções sociais que fazem parte dos processos políticos organizacionais. Ao construir essas condições, efeitos de poder-saber são gerados, assim como atores organizacionais constroem condições para legitimar ou limitar as ações (LECLERCQ-VANDELANNOITTE, 2011).

Esta retomada teórica do que seria Arqueologia de Discurso de Foucault, juntamente com a demonstração empírica teve por finalidade evidenciar outras possibilidades de AD em Estudos Organizacionais, além da já estabelecida ACD. Ressaltamos, contudo, que o "olhar" do pesquisador para com o objeto difere entre estas abordagens. A seguir, discutiremos teoricamente a respeito de outro tipo de AD, no caso a Análise Conversacional, seguido de uma demonstração empírica.

\section{Análise Conversacional}

A Análise Conversacional teve em sua constituição forte influência da perspectiva institucional sócio-interacional de Erving Goffman (1983), que concebe as interações não como algo sem tensões e que poderiam ser entendidas a partir de padrões matemáticos de interseções entre atores sociais, mas sim como uma matriz densa de entendimentos, convenções normativas e procedimentos inferenciais que serve para (in)formar interações entre pessoas específicas em um contexto situacional particular. A interação social incorpora uma ordem institucional e moral e é, para o autor, uma complexa configuração de direitos e deveres interacionais, que são incorporados e estão ligados tanto à identidade pessoal, em um nível mais micro, quanto a instituições sociais em larga escala, no âmbito mais macro (HERITAGE, 2004).

A partir da contribuição de Goffman (1983) a Análise Conversacional foi fundada, partindo da premissa de que a conversação é o local primordial da sociabilidade humana, uma vez que ela media a operacionalização de todas as instituições humanas, sendo inclusive anterior ao desenvolvimento das sociedades. As práticas de interação conversacional estão direcionadas para questões fundamentais de gerenciamento da comunicação humana e das relações sociais, incluindo questões como identificar e distribuir as unidades de fala que compõem os turnos na conversação, fazer referência a objetos, pessoas e lugares, localizar e fixar problemas de fala, escuta e entendimento, gerenciar solidariedade e afiliação social em relações sociais, dentre outras que constituem parte significativa do habitus humano (HERITAGE, 2011).

A Análise Conversacional também deve ser entendida como uma técnica advinda da etnometodologia, uma vez que seu foco de estudo está voltado para ações, no caso falas ou diálogos, que ocorrem na prática cotidiana. Seu principal objetivo é estudar a fala natural que se apresenta em um contexto institucional e, para tanto, analisa dentro deste contexto a ação e a intersubjetividade. Estas noções podem ser compreendidas a partir de interações seqüenciais, nas quais há uma junção entre contexto e sentido, de modo que a ação seja influenciada por uma ação anterior, mas também crie contexto para uma ação futura. As interações seqüenciais abarcam as interações institucionais, que se orientam para objetivos e para o desempenho de papéis ou identidades (HERITAGE, 2004). Deste modo, na Análise Conversacional o foco está na organização sequencial e não na organização retórica, muito embora a organização sequencial seja um pré-requisito para a organização retórica (POTTER, 2003). 
Para Heritage (2004), a institucionalidade da conversação pode ser observada pela organização dos turnos da conversa, pela estrutura geral da interação, pela organização sequencial, pelo desenho dos turnos, pela escolha das palavras utilizadas e pelas assimetrias interacionais. Estes elementos estão explicitados a seguir.

A organização dos turnos da conversa se refere à troca de turnos que acontece nos diálogos e é um importante fator no estudo da interação institucional, dado que podem ter o potencial de alterar as oportunidades para a ação e de ajustar a interpretação de quase todo o aspecto das atividades estruturadas pela interação. A estrutura geral da interação pode ser compreendida como uma espécie de mapa da interação em termos de frases ou seções típicas. Todavia, seu propósito não é o de descobrir regularidades invariantes que orientem estas seções, mas sim descrevê-las para identificar as orientações que os participantes co-constroem rotineiramente em seu cotidiano. Já a organização sequencial trata do significado das ações específicas que são organizadas nas sequências que os participantes iniciam, desenvolvem e concluem suas interações. Aqui é importante olhar para como os cursos de ações são iniciados e desenvolvidos e como oportunidades de ações são abertas e ativadas, ou retidas e obstruídas.

Sobre o desenho dos turnos é importante destacar dois aspectos do discurso: 1) a ação que a fala é designada a desempenhar e 2) os significados que são selecionados para desempenhar a ação. Em outras palavras, o primeiro sentido em que um turno é desenhado diz respeito à seleção de uma ação que alguém quer realizar em um turno da conversa. $\mathrm{O}$ segundo sentido do desenho de turno se refere ao fato dos integrantes também selecionarem meios alternativos para dizer alguma coisa ou desempenhar a mesma ação. A escolha léxica é um importante componente do desenho de turno e é, em geral, orientada pelo contexto institucional e pela natureza do interlocutor, contudo, nem sempre é uma escolha consciente ou voluntária, já que algumas ações podem estar tão internalizadas que se tornam naturalizadas.

Por fim, as assimetrias de interação envolvem os seguintes tipos de assimetria: 1) de participação, podendo significar uma desigualdade na interação, principalmente quando um dos participantes possui uma posição profissional superior; 2) de "know-how" institucional e interacional, que ocorre quando para uma das partes a interação faz parte da rotina, mas para a outra parte significa um caso especial e único, podendo lhe gerar certa tensão; 3) de conhecimento ou epistemológica, quando profissionais e representantes institucionais se utilizam de seu conhecimento especializado, e geralmente ignorado pelo(s) outro(s) participante(s), a fim de fazer prevalecer sua autoridade ou seu domínio de conhecimento e 4) de direito de acesso ao conhecimento, quando pessoas leigas ou de parcos recursos têm informações que são relevantes, mas não têm o direito de sabê-las ou tiveram conhecimento delas por meio censurável.

Assim, a Análise Conversacional pode ser condensada em três princípios básicos: sequência, prática e organização. A ideia básica da sequência é a de que o contexto no qual ocorre um turno de fala está localizado no turno imediatamente anterior a ele. Essa contextualização da conversação, que se dá turno a turno, é um recurso vital para a construção de entendimento na interação. O segundo princípio se impõe na medida em que a Análise Conversacional investiga a interação a partir das práticas que os participantes usam para construí-la. Uma prática é qualquer característica presente no desenho de um turno, dentro de uma sequência, que tem um caráter distinto, que tem uma localização específica dentro de um turno ou sequência e é distinta em termos de consequências para a natureza ou significado de uma ação que um turno implementa. Já o princípio da organização faz referência aos agrupamentos das práticas encontradas pela Análise Conversacional, que são dispostos em conjuntos organizados que concentram a ordem fundamental da organização conversacional e interacional (HERITAGE, 2010). 
Para melhor compreender este método, Heritage (2010) assevera que é necessário não perder de vista que ele foi delineado para lidar com características fundamentais da ação e interação humana. Deste modo, é importante destacar que, dentre outras características, as ações humanas são significativas e constroem significados, alcançando esses significados através de uma combinação de seu conteúdo e contexto e também na medida em que estes significados são compartilhados socialmente, muito embora sejam únicos e singulares. Assim, as ações funcionam de determinada maneira para criar significados que são particulares, mas socializados.

Potter (2003) argumenta que em conversas que ocorrem naturalmente, como é o caso da Análise Conversacional, este tipo de fala se refere a produções de linguagens que ocorrem independentes da ação do pesquisador, tais como conversas ao telefone, gravações de reuniões corporativas, comportamentos em sala de aula (AMUNDRUD, 2011) ou interações entre médicos e pacientes (HERITAGE, 2011). Assim, a naturalidade deste tipo de conversa não se deve ao fato da mesma não possuir elementos que a condicionem de alguma forma, como, por exemplo, o contexto institucional de uma reunião empresarial ou a assimetria de conhecimento entre médico e paciente, mas sim ao fato dela acontecer sem a intervenção do pesquisador, seja por meio de questionários, roteiros de entrevistas ou demais protocolos de pesquisa.

No Brasil, ainda não foram efetuados estudos que optassem metodologicamente pela análise conversacional. Mesmo no âmbito internacional, sua utilização em pesquisas organizacionais ainda é incipiente, contudo, vários estudos vêm sendo realizados nas áreas da sociologia, psicologia e linguagem (GARCIA, 1991; MAYNARD, 1991; HERITAGE; LINDSTRÖM, 1998; WHALEN; ZIMMERMAN, 1998; CLAYMAN; HERITAGE, 2002; HERITAGE, 2011; AMUNDRUD, 2011).

Em função disto, escolhemos para exemplificar a análise conversacional em termos empíricos, o artigo de Angela Garcia (1991) que trata sobre resolução de conflitos/ disputas em audiências de conciliação. A escolha por este estudo se refere ao fato do tema em questão - resolução de conflitos e mediação- estar presente no dia-a-dia das práticas organizacionais.

O estudo parte do pressuposto de que o conflito pode ser solucionado por meio de confrontações ou argumentações mínimas, em parte devido à mediação que consegue suavizar a natureza adversativa da situação e encorajar a cooperação. Assim, a pesquisa tem por objetivo mostrar como a mediação promove concordância e minimiza argumentos na resolução de discussões. Para tanto, faz uma análise da organização interacional de audiências de conciliação, que restringe como as acusações e negações são posicionadas e formuladas, e a compara com a organização dos turnos na conversação comum, ou seja, no conflito que ocorre sem mediação e que comumente se vale de técnicas de argumentação.

A pesquisa avaliou o programa de conciliação proposto pelo estado da Califórnia, que serve como uma alternativa para os tribunais de pequenas causas. Foram gravadas todas as audiências que ocorreram durante um período de seis meses no ano de 1987, totalizando nove audiências. Todos os envolvidos foram informados da pesquisa e concordaram com a gravação. Ao total, mais de 20 horas de áudio foram transcritas. Cabe ressaltar que as transcrições na Análise Conversacional acontecem segundo uma codificação específica que sinaliza na fala a respiração (.hh hh), as sílabas em que há prolongamentos (fa:la), ênfase em uma palavra ( $\underline{\text { muito }}$ ), aumento de volume (VOCÊ), diminuição de volume (onãoo), tempo de pausa em segundos (1.4), palavras não compreendidas ( ), palavras ligadas em outras ( $\operatorname{sim}=)$, simultaneidade nas falas (A: [uma cópia]; B: [Eu tenho]), dentre outras sinalizações. A fim de exemplificar, reproduziremos aqui um trecho do artigo que trata de uma conversa comum, que foi gravada por um dos disputantes e levada à audiência de conciliação: 
Trecho 1:

1 Stan: I want to talk to you $(\quad)=$

2 Karen: =I DI:DN'T: (.3) HAVE $\underline{\text { ANYTHING,= }}$

3 Stan: =YOU HAD (RIGHT) TO DO WITH=IT!

4 Stan: [(YOU ARE ALWAYS)]

5 Karen: [YOU KNOW THAT IS] BULL I DIDN`T

6 Stan: [YOU ALLOWED IT]

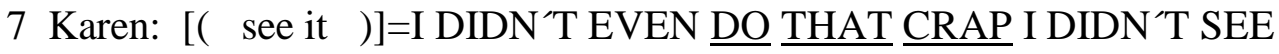

8 THAT.

A estrutura destas conversas, chamadas de conversas comuns, foram analisadas a partir de dois elementos: 1) preferência para concordância e 2) manutenção e aumento de disputa. Já o sistema de discurso da mediação foi analisado a partir de quatro pontos: 1) mudança de turno, uma vez que esta mudança era pré-estabelecida, já que os disputantes não poderiam interromper o outro durante sua fala, mas o mediador poderia; 2 ) enquadramento da participação, dado que a participação também era pré-determinada, posto que os disputantes não poderiam se referir um ao outro, mas sim ao mediador; 3) formato da discussão, na qual o mediador controlava os tópicos e quem dele participava e 4) desvios da estrutura discursiva da mediação para a estrutura de uma conversação comum, o que ocorria eventualmente.

Todos esses elementos se diferenciam da estrutura de organização discursiva que acontece em uma conversação comum, já que a mudança de turno, a participação e o formato da discussão em conflitos que acontecem sem mediação, ocorrem com maior naturalidade. Embora a utilização da Análise Conversacional neste caso possa parecer inapropriada, já que a estrutura das falas se difere daquela que acontece na conversação comum, a escolha se mostra pertinente na medida em que capta como as diferenças na organização dos turnos e as assimetrias na participação, elementos estes que são privilegiados na Análise Conversacional, podem influenciar na minimização da argumentação. A seguir, reproduzimos um trecho do artigo que se refere às conversas com mediação, ocorridas na audiência de conciliação:

Trecho 2:

R. Because we have A:LL had repeated?,(.6) up sets?, (.3) from Mrs. oNortono (.8) A::nd, if there would be some way to work this ou::t!, I would li::ke to do it:. (.2) bu::t, (.3) I don't fee::1, and no one else feels because $(1,9)$ A:LL the reasons that-s:h[e claimed]

M: [Have you] seen this? (.2)

C: No, I haven't?

O estudo conclui que a vantagem da mediação quando comparada com outros tipos de resolução de conflitos, como por exemplo, julgamentos, aconselhamentos e questionamentos, reside não nas características do mediador ou na dificuldade da disputa, mas sim na organização interacional da própria mediação. Isto se reflete no retardamento das colocações de negação, na referência ao mediador, ao invés de se reportar à outra parte envolvida, e na ordem normativa de cooperação e não-adversidade encorajada pela mediação. Todos estes aspectos fazem com que a mediação consiga deter o excesso de argumentação nas disputas, diferentemente do que acontece em uma conversação comum. Assim, a interação é condicionada pela mediação que organiza os turnos e altera as oportunidades para as ações, a partir da escolha léxica e das assimetrias de interação, neste caso assimetria de participação.

Com isso, procuramos mostrar como a Análise Conversacional pode se revelar interessante para os estudos organizacionais na medida em que permite captar como os elementos institucionais podem estar internalizados a ponto de serem percebidos seja em uma 
conversa que ocorre naturalmente, seja em uma conversa mediada e, a partir daí, ser analisada a influência destes elementos na ação dos sujeitos e nos diversos papéis que desempenham. Todavia, na academia brasileira a contribuição que a Análise Conversacional pode oferecer aos estudos organizacionais ainda não foi explorada, representando um campo metodológico de considerável potencial a ser desenvolvido.

\section{Discussão e Considerações Finais}

Este ensaio teve por objetivo retomar o debate em AD a fim de levantar possibilidades menos exploradas na academia brasileira, como a Arqueologia do Discurso (FOUCAULT, 1972; 2002) e a Análise Conversacional (HERITAGE, 2004; 2011), em estudos organizacionais. Primeiramente, apontamos a prevalência da ACD nas pesquisas do campo reforçando a pouca utilização de outros métodos. Em seguida, nos voltamos para uma discussão dos principais conceitos em ACD, Arqueologia do discurso e Análise Conversacional, destacando nestas duas últimas possibilidades em pesquisas empíricas na área.

Este debate evidenciou a importância da $\mathrm{AD}$ e como esta possui diferentes perspectivas e papéis com três vieses centrais: como "método" de pesquisa, como "campo" de estudo teórico e como "objeto" de estudo (ALVESSON; KARREMAN, 2011). Isto é ressaltado inclusive no uso de diferentes conceitos da palavra "discurso" para distintos autores (CLEGG, 1989; VAN DIJK, 1993; POTTER, 2003; GRANT et al., 2004; FAIRCLOUGH, 2005a).

Para além da ACD como abordagem predominante de AD, podemos apontar como relevantes, ainda que poucos estudos realizados sob as perspectivas da Arqueologia do Discurso e da Análise Conversacional. Como principais contribuições da Arqueologia temos a possibilidade de analisar como ocorre o processo de formação discursiva por meio das "práticas discursivas"/"recursos discursivos". Ou seja, quais são as relações que favorecem o surgimento de um discurso com "D" maiúsculo. Tais relações não se encontram no discurso em si, mas no seu limite, e caracterizam o discurso enquanto prática. Partindo do pressuposto de que a história deve mostrar que o que é jamais foi, Foucault (2000a) defende que a partir do conhecimento de como as coisas foram feitas é possível que se saiba também como elas podem ser desfeitas.

Já sobre a Análise Conversacional temos a possibilidade de compreender como elementos institucionais passam a ser internalizados no discurso sendo percebidos até mesmo em uma conversa que ocorre naturalmente, e a partir deste entendimento podemos analisar a influência destes elementos na ação dos sujeitos e nos diferentes papéis desempenhados. Por isto seu foco está na organização sequencial da fala natural que se apresenta em um contexto institucionalizado.

A demonstração dos estudos empíricos reforçou as possibilidades de pesquisa empírica com a utilização destes métodos. O estudo de Leclercq-Vandelannoitte (2011) problematiza o postulado de que a comunicação constitui as organizações (CCO Communication Constitutes Organizations), com objetivo de evidenciar a natureza das relações de $\mathrm{CCO}$ com base em uma abordagem foucaultiana. Efetuada a parte empírica, os resultados sugerem que a constituição de uma organização ocorre no contexto das condições dinamicamente possíveis e restritas, constituindo-se em práticas discursivas e incorporadas em recursos materiais. Já a pesquisa de Garcia (1991) se vale da Análise Conversacional para sustentar que a mediação, em audiências de conciliação, pode ajudar a solucionar conflitos, dado as características de sua estrutura organizacional discursiva e interacional, que pode contribuir para minimizar as excessivas argumentações que ocorrem em conflitos que 
acontecem em conversações comuns, isto é, sem a presença da mediação. Para melhor visualização das diferenças entre estas três perspectivas, apresentamos o quadro 1 com destaque para as principais características.

Quadro 1 - Características e diferenças das três perspectivas

\begin{tabular}{|l|l|l|l|}
\hline & $\begin{array}{l}\text { Análise Crítica } \\
\text { do Discurso }\end{array}$ & $\begin{array}{l}\text { Arqueologia do } \\
\text { Discurso }\end{array}$ & $\begin{array}{l}\text { Análise } \\
\text { Conversacional }\end{array}$ \\
\hline $\begin{array}{l}\text { Orientação } \\
\text { epistemológica }\end{array}$ & $\begin{array}{l}\text { Realismo } \\
\text { Crítico }\end{array}$ & $\begin{array}{l}\text { Pós- } \\
\text { estruturalismo } \\
\text { foucaltiano }\end{array}$ & Etnometodologia \\
\hline Autor chave & $\begin{array}{l}\text { Norman } \\
\text { Fairclough }\end{array}$ & Michel Foucault & John Heritage \\
\hline Foco de análise & $\begin{array}{l}\text { Relação } \\
\text { linguagem e } \\
\text { poder }\end{array}$ & $\begin{array}{l}\text { Episteme/ macro } \\
\text { ideologia }\end{array}$ & $\begin{array}{l}\text { Discurso } \\
\text { institucionalmente } \\
\text { situado }\end{array}$ \\
\hline $\begin{array}{l}\text { Dados } \\
\text { privilegiados }\end{array}$ & $\begin{array}{l}\text { Práticas sociais, } \\
\text { instituições, } \\
\text { contextos mais } \\
\text { amplos } \\
\text { ideológicos }\end{array}$ & $\begin{array}{l}\text { Análises } \\
\text { históricas, } \\
\text { materialidade }\end{array}$ & $\begin{array}{l}\text { Conversa natural } \\
\text { /institucionalmente } \\
\text { inserida }\end{array}$ \\
\hline
\end{tabular}

Fonte: Elaborado pelos autores com base em Peci (2012) - notas de aula.

Entendemos que o objetivo deste ensaio foi alcançado, no sentido de propor para discussão outras possibilidades de abordagens sobre AD em estudos organizacionais, que possam trazer maior contribuição para o desenvolvimento metodológico do campo. Sugerimos que a partir deste estudo possam ser desenvolvidas novas pesquisas com abordagens menos usuais em $\mathrm{AD}$, de forma a permitir maior amplitude e pluralidade, afinal, como pesquisadores, não estaríamos reduzindo a $\mathrm{AD}$ apenas à $\mathrm{ACD}$ ?

\section{Referências}

ALVESSON, M.; KÄRREMAN, D. Varieties of discourse: On the study of organizations through discourse analysis. Human Relations, v. 53, n. 9, p. 1125-1149, 2000a.

ALVESSON, M.; KÄRREMAN, D. Taking the linguistic turn in organizational research: Challenges, responses, consequences. Journal of Applied Behavioural Science, v. 36, n. 2, p. 134-156, 2000b.

ALVESSON, M.; KÄRREMAN, D. Decolonializing discourse: Critical reflections on organizational discourse analysis. Human Relations, v. 64, n. 9, p. 1-26, 2011.

AMUNDRUD, T. On Observing Student Silence. Qualitative Inquiry, v. 17, n. 4, p. $334-$ $342,2011$.

ASHCRAFT, K.; KUHN, T.; COOREN, F. Constitutional amendments: Materializing organizational communication. Academy of Management Annals, v. 3, n. 1, p. 1-64, 2009.

BARROS, D.; COSTA, A.; PEREIRA, S.; AYROSA, E. O Consumidor "Ecologicamente Correto": Interpretações do Argumento Ecológico Organizacional. In: XIV CONGRESSO BRASILEIRO DE SOCIOLOGIA, 2009. Rio de Janeiro. Anais... Rio de Janeiro, RJ, 28 a 31 de julho de 2009. 
BURRELL, G. Ciência Normal, Paradigmas, Metáforas, Discursos e Genealogia da análise. In: CLEGG, S. (Org.). Handbook de estudos organizacionais. São Paulo: Atlas, 1998.

CALÁS, M; SMIRCICH, L. Voicing Seduction to Silence Leadership. Organization Studies, v. 12, n. 4, p. 567-602, 1991.

CHOULIARAKI, L.; FAIRCLOUGH, N. Critical discourse analysis in organizational studies: towards an integrationist methodology. Journal of Management Studies, v. 47, n. 6, p. $1213-8,2010$.

CLAYMAN, S; HERITAGE, J. Questioning Presidents: journalistic deference and adversarialness in the press conferences of U.S. presidents Eisenhower and Reagan. Journal of Communication, v. 52, n. 4, p. 749-775, 2002.

CLEGG, S. Frameworks of Power. London: SAGE, 1989.

COOPER, R.; BURRELL, G. Modernismo, pós-modernismo e análise organizacional: uma introdução. In: CALDAS, M.; BERTERO, C. (Orgs.). Teoria das Organizações. São Paulo: Atlas, 2007.

FAIRCLOUGH, N. Language and Power. New York: Longman, 1989.

FAIRCLOUGH, N. Critical discourse analysis and the marketization of public discourse: the Universities. Discourse and Society, v. 4, n. 2, p. 133-68, 1993.

FAIRCLOUGH, N. Critical Discourse Analysis. London: Longman, 1995.

FAIRCLOUGH, N. Discourse, social theory and social research: the discourse of welfare reform. Journal of Sociolinguistics, v. 4, n. 2, p. 163-195, 2000.

FAIRCLOUGH, N. Discurso e mudança social. Brasília: Editora UnB, 2001.

FAIRCLOUGH, N. Analysing Discourse: Textual Analysis for Social Research. London: Routledge, 2003.

FAIRCLOUGH, N. Peripheral vision: Discourse analysis in organization studies: The case for critical realism. Organization Studies, v. 26, n. 6, p. 915-939, 2005a.

FAIRCLOUGH, N. Critical Discourse Analysis. Marges Linguistiques, v. 9, p. 76-94, 2005b.

FAIRCLOUGH, N.; WODAK, R. Critical Discourse Analysis. In: VAN DIJK, T. (Org.). Discourse as Social Interaction. London: Sage, 1997.

FAIRHURST, G. Discursive Leadership. Thousand Oakes: SAGE, 2007.

FAIRHURST, G.; PUTNAM, L. Organizations as discursive constructions. Communication Theory, v. 14, n. 1, p. 5-26, 2004.

FAUBION, J. Aesthetics, Method, and Epistemology. Paris: Editions Gallimard, 1994. 
FONSECA, M. Foucault e o Direito. 2001. Tese de Doutorado - Faculdade de Direito da Universidade de São Paulo, Universidade de São Paulo, São Paulo, 2001.

FOUCAULT, M. A arqueologia do saber. Lisboa; Porto: Vozes, 1972.

FOUCAULT, M. O nascimento da clínica. Rio de Janeiro: Forense Universitária, 1998.

FOUCAULT, M. Estruturalismo e Pós-estruturalismo. In: Ditos \& Escritos, v. II:

Arqueologia das Ciências e História dos Sistemas de Pensamento. Rio de Janeiro, ed. Forense Universitária, 2000a.

FOUCAULT, M. Michel Foucault explica seu último livro. In: Ditos \& Escritos, v. II:

Arqueologia das Ciências e História dos Sistemas de Pensamento. Rio de Janeiro, ed. Forense Universitária, 2000b.

FOUCAULT, M. História da loucura na Idade Clássica. São Paulo: Perspectiva, 2002.

GARCIA, A. Dispute resolution without disputing: how the interactional organization of mediation hearings minimizes argument. American Sociological Review, v. 56, n. 6, p. 818$835,1991$.

GIDDENS, A. Modernity and Self-Identity. Cambridge: Polity Press, 1990.

GILL, R. Análise de discurso. In: BAUER, M.; GASKELL, G. (Orgs.). Pesquisa Qualitativa com texto, imagem e som. Petrópolis, RJ: Vozes, 2002.

GOFFMAN, E. The Interaction Order. American Sociological Review, v. 48, p. 1-17, 1983.

GRANT, D.; HARDY, C.; OSWICK, C.; PUTNAM, L. Handbook of Organizational

Discourse. London: SAGE, 2004.

HARDY, C.; LAWRENCE, T.; GRANT, D. Discourse and collaboration: The role of conversations and collective identity. Academy of Management Review, v. 30, n. 1, p. 58$77,2005$.

HARVEY, D.; REED, M. Social science as the study of complex systems. Chaos theory in the social sciences, p. 295-324, 1996.

HERITAGE, J. Conversation Analysis and Institutional Talk: Analyzing data. In: SILVERMAN, D. (Org.). Qualitative Research: Theory, Method and Practice. London: Sage, 2004.

HERITAGE, J. Conversation Analysis: Practices and Methods. In: SILVERMAN, D. (Org.). Qualitative Research: Theory, Method and Practice. London: Sage, 2010.

HERITAGE, J. The interaction order and clinical practice: Some observations on dysfunctions and action steps. Patient Education and Counseling, v. 84, n. 3, p. 338-343, 2011. 
HERITAGE, J.; LINDSTRÖM, A. Motherhood, medicine, and morality: scenes from a medical encounter. Research on Language and Social Interaction, v. 31, n. 3-4, p. 397-438, 1998.

KNIGHTS, D.; MORGAN; G. Corporate strategy, organizations, and subjectivity: a critique. Organization Studies, v. 12, n. 2, p. 251-273, 1991.

LECLERCQ-VANDELANNOITTE, A. Organizations as Discursive Constructions: A Foucauldian Approach. Organization Studies, v. 32, n. 9, p. 1247-1271, 2011.

MAYNARD, D. Interaction and Asymmetry in Clinical Discourse. American Journal of Sociology, v. 97, n. 2, p. 448-495, 1991.

McPHEE, R., ZAUG, P. The communicative constitution of organizations: A framework for explanation. Electronic Journal of Communication, v. 10, n. 1-2, p. 1-2, 2000.

MOTTA, F.; ALCADIPANI, R. O pensamento de Michel Foucault na teoria das organizações. Rausp, v. 39, n. 2, p. 117-128, 2004.

MUMBY, D. Discourse, power and ideology: unpacking the critical approach. In: GRANT, D., HARDY, C., OSWICK, C., PUTNAM, L. (Orgs.). The Sage Handbook of Organizational Discourse. London: Sage, 2004.

PECHÊUX, M. Language, Semantics and Ideology. London: MacMillan, 1982.

PECI, A. Discursos e a construção do "real": um estudo do processo de formação e institucionalização do campo da biotecnologia. 2005. $233 \mathrm{f}$. Tese de Doutorado em Administração - Escola Brasileira de Administração Pública e de Empresas, Fundação Getulio Vargas, Rio de Janeiro, 2005.

PEDROSA, C. Análise Crítica do Discurso: uma Proposta para a Análise Crítica da Linguagem. In: IX CONGRESSO NACIONAL DE LINGÜÍSTICA E FILOLOGIA, 2005, UERJ. Rio de Janeiro. Anais... Rio de Janeiro. Disponível em:

<http://www.filologia.org.br/ixcnlf/3/04.htm>. Acesso em: 5 de setembro de 2010.

PHILLIPS, N.; HARDY, C. Discourse Analysis: Investigating Processes of Social Construction. Thousand Oaks, CA: Sage, 2002.

POTTER, J. Discursive psychology: Between method and paradigm. Discourse \& Society, v. 14, n. 6, p. 783-794, 2003.

RABINOW, P.; DREYFUS, H. Michel Foucault: Uma Trajetória Filosófica para Além do Estruturalismo e a Hermenêutica. Rio de Janeiro: Forense Universitária, 1995.

SILVERMAN, D. (Org.). Qualitative Research: Theory, Method and Practice. London: Sage, 2004.

SMITH, R. Images of organizational communication: Root metaphors of the organizationcommunication relation. Annual conference of the international communication association, Washington, DC, 1993.

“Terra à Vista!”: Explorando Outras Possibilidades em Análise do Discurso em Estudos Organizacionais 
TITSCHER, S.; JENNER, Bryan. Methods of text and discourse analysis: In search of meaning. Sage, 2000.

TOWNLEY, B. Foucault, power/knowledge, and its relevance for human resource management. Academy of Management Review, v. 18, n. 3, p. 518-545, 1993.

VAN DIJK, T. Principles of critical discourse analysis. Discourse and Society, v. 4, n. 2, p. 249-283, 1993.

VAN DIJK, T. Discourse, context and cognition. Discourse Studies, v. 8, n. 1, p. 159-77, 2006.

WHALEN, J.; ZIMMERMAN, D. Observations on the display and management of emotion in naturally occurring activities: the case of "hysteria" in calls to 9-1-1. Social Psychology Quaterly, v. 61, n. 2, p. 141-159, 1998.

WODAK, R.; MEYER, M. Methods of Critical Discourse Analysis. London: Sage, 2001. 